\title{
Collections of Puccinia triticina in Different Provinces of China Are Highly Related for Virulence and Molecular Genotype
}

\author{
J. A. Kolmer
}

U.S. Department of Agriculture-Agriculture Research Service, Cereal Disease Laboratory, St. Paul, MN 55108.

Accepted for publication 7 January 2015.

\begin{abstract}
Kolmer, J. A. 2015. Collections of Puccinia triticina in different provinces of China are highly related for virulence and molecular genotype. Phytopathology 105:700-706.

Collections of Puccinia triticina, the wheat leaf rust pathogen, were obtained from seven provinces in China from 2009 and 2010. Single uredinial isolates were derived and tested for virulence phenotype to 20 lines of Thatcher wheat that differ for single leaf rust resistance genes, and for molecular genotype with 23 simple sequence repeat (SSR) primers. Fortyeight virulence phenotypes were described among the 155 isolates tested for virulence. All but four isolates were virulent to $\operatorname{Lr} 26$, and no isolates with virulence to $L r 18$ or $L r 24$ were found. The three most common phenotypes,
\end{abstract}

ABSTRACT
FCBQQ, PCGLN, and PCGLL, were found in five, five, and three provinces, respectively. Thirty-six SSR genotypes were found among the 100 isolates tested for molecular variation. Isolates with identical virulence phenotypes and SSR genotypes were found in more than one province. Analysis of variation showed no overall differentiation of SSR genotypes or virulence phenotypes based on province of origin. The SSR genotypes had high levels of linkage disequilibrium, high levels of observed heterozygosity, and significant correlation with the virulence phenotypes, all measures that indicated clonal reproduction. Bayesian cluster analysis and principle component plots indicated three groups of SSR genotypes that also varied significantly for virulence. The seven provinces are continuously adjacent to each other and likely form a single epidemiological zone for P. triticina.
Leaf rust of wheat caused by Puccinia triticina Erikss. is the most common rust of wheat (Triticum aestivum L.) worldwide (Roelfs et al. 1992). The leaf rust disease is most severe in coastal regions where wheat grows and matures in warm humid conditions such as Turkey (Kolmer et al. 2013) and Uruguay (German and Kolmer 1994; German et al. 2007) and also in continental regions that have warm to hot summer temperatures such as the Great Plains of North America (Roelfs 1989) and Central Asia (Morgounov et al. 2007). Physiologic specialization in P. triticina has been studied extensively in the United States (Johnston et al. 1968) and Canada (Johnson 1956) since the 1930s. Populations of $P$. triticina are highly variable as many virulence phenotypes of the fungus are found on an annual basis almost wherever virulence surveys are conducted (Chester 1946). Virulent isolates of $P$. triticina can increase and spread rapidly over a wide geographic area in response to wheat cultivars that have resistance genes that are effective to specific leaf rust phenotypes. The wide climatic adaptation coupled with the high degree of virulence variation has made long lasting resistance to leaf rust difficult to achieve.

China was the leading wheat producing country in the world in 2014 with 122 million tons harvested from 24 million hectares (USDA-FAS). Wheat is the most widely distributed crop in China (Baoqi et al. 2001), with the largest production areas concentrated in the Yellow, Huai, and Yangtze River Valleys in the eastern and southeastern regions. Wheat leaf rust occurs regularly in China affecting millions of hectares of wheat. Virulence surveys of P. triticina were initiated in 1940 in China (Wang 1947) and have continued to the present day (Liu and Chen 2012).

Corresponding author: J. A. Kolmer; E-mail address: Jim.Kolmer@ars.usda.gov

*The $\boldsymbol{e}$-Xtra logo stands for "electronic extra" and indicates that one supplementary figure and three supplementary tables are published online.

http://dx.doi.org/10.1094/PHYTO-11-14-0293-R

This article is in the public domain and not copyrightable. It may be freely reprinted with customary crediting of the source. The American Phytopathological Society, 2015.
Populations of $P$. triticina from other major wheat producing world regions (Goyeau et al. 2007; Kolmer and Ordoñez 2007; Kolmer et al. 2011, 2012; Ordoñez and Kolmer 2009; Ordoñez et al. 2010) have been characterized by groups of isolates that are distinct for virulence phenotypes and also for allele variation at microsatellite or simple sequence repeat (SSR) loci. In all of these studies populations of $P$. triticina had high levels of observed heterozygosity at SSR loci, a high degree of linkage disequilibria between SSR loci, and a significant correlation between SSR genotypes and virulence phenotypes. These are all characteristics of populations that reproduce by the clonal production of urediniospores. The most compatible alternate host for $P$. triticina, Thalictrum speciosissimum $\mathrm{L}$. is found mostly in the Mediterranean region of southwestern Europe (Samborski 1985). Despite the lack of suitable alternate hosts throughout most of the world, $P$. triticina has flourished as a successful pathogen of wheat. In this study collections of $P$. triticina from different provinces of China were characterized for virulence using a standard set of host differential lines and also for variation at SSR loci with a standard set of primer pairs. The objectives were to determine if regional populations of $P$. triticina were present in China and if distinct groups of isolates based on virulence phenotype and SSR genotype were present. The ultimate goal of this study and previous related work were to characterize worldwide populations of the leaf rust fungus in order to determine their genetic relationships and to provide further insight on the movement and diversity of this important wheat pathogen.

\section{MATERIALS AND METHODS}

Collections of $P$. triticina were obtained from the College of Plant Protection, Agricultural University of Hebei, Baoding, Hebei, China. Collections were from locations in Shanxi, Sichuan, Anhui, Hebei, Henan, and Shandong provinces in 2009, and Hubei province in 2010 (Fig. 1, Supplementary Table 1). Ten collections from three to eight locations were obtained from each province in 2009 and collections came from two locations in Hubei province in 2010. The collections were bulk samples of uredinia from the different provinces that had been used for screening wheat 
germplasm for leaf rust resistance. Three single uredinial isolates were derived from each collection and increased as previously described (Kolmer and Hughes 2013). Urediniospores were dried in a desiccator for 2 days and stored at $-80^{\circ} \mathrm{C}$.

Each single uredinial isolate was inoculated as previously described (Kolmer and Hughes 2013) on seedlings of Thatcher wheat lines that are near-isogenic for leaf rust resistance genes. Five sets of four differentials were used. Set 1 was lines with genes $\mathrm{Lrl}$ (isogenic line RL6003), Lr2a (RL6000), Lr2c (RL6047), and Lr3 (RL6002); set 2, Lr9 (RL6010), Lr16 (RL6005), Lr24 (RL6064), and Lr26 (RL6078); set 3, Lr3ka (RL6007), Lrl1 (RL6053), Lr17 (RL6008), and Lr30 (RL6049); set 4, LrB (RL6047), Lr10 (RL6004), Lr14a (RL6013), and Lrl8 (RL6009); and set 5, Lr3bg (RL6042), Lr14b (RL6006), Lr20 (RL 6092), and Lr28 (RL6079). Thatcher was included as a susceptible control. Infection types 0 to $2^{+}$(immune response to moderate to large uredinia with necrosis or chlorosis) were classified as avirulent, and infection types 3 to 4 (moderate to large uredinia without chlorosis or necrosis) were classified as virulent. Each isolate was assigned a five letter designation based on the hexadecimal code adapted for virulence nomenclature of $P$. triticina in North America (Long and Kolmer 1989). Each isolate was designated with a 20 digit binary number based on virulence/avirulence on each of 20 host differential lines. A total of 155 isolates were tested for virulence phenotype. Differences in virulence among provinces were measured with a modified Nei's genetic distance (Nei 1972) with virulence frequency to each $\mathrm{Lr}$ gene replacing allele frequency.

DNA was extracted from the single uredinial isolates using the OmniPrep (G-BioSciences, St. Louis, MO) extraction kit. Twentythree microsatellite pairs (Duan et al. 2003; Szabo and Kolmer 2007) developed from genomic libraries were used to determine the molecular genotypes. Amplification and electrophoresis were carried out as previously described (Szabo and Kolmer 2007). Allele sizes in base pairs were scored visually for each primer pair

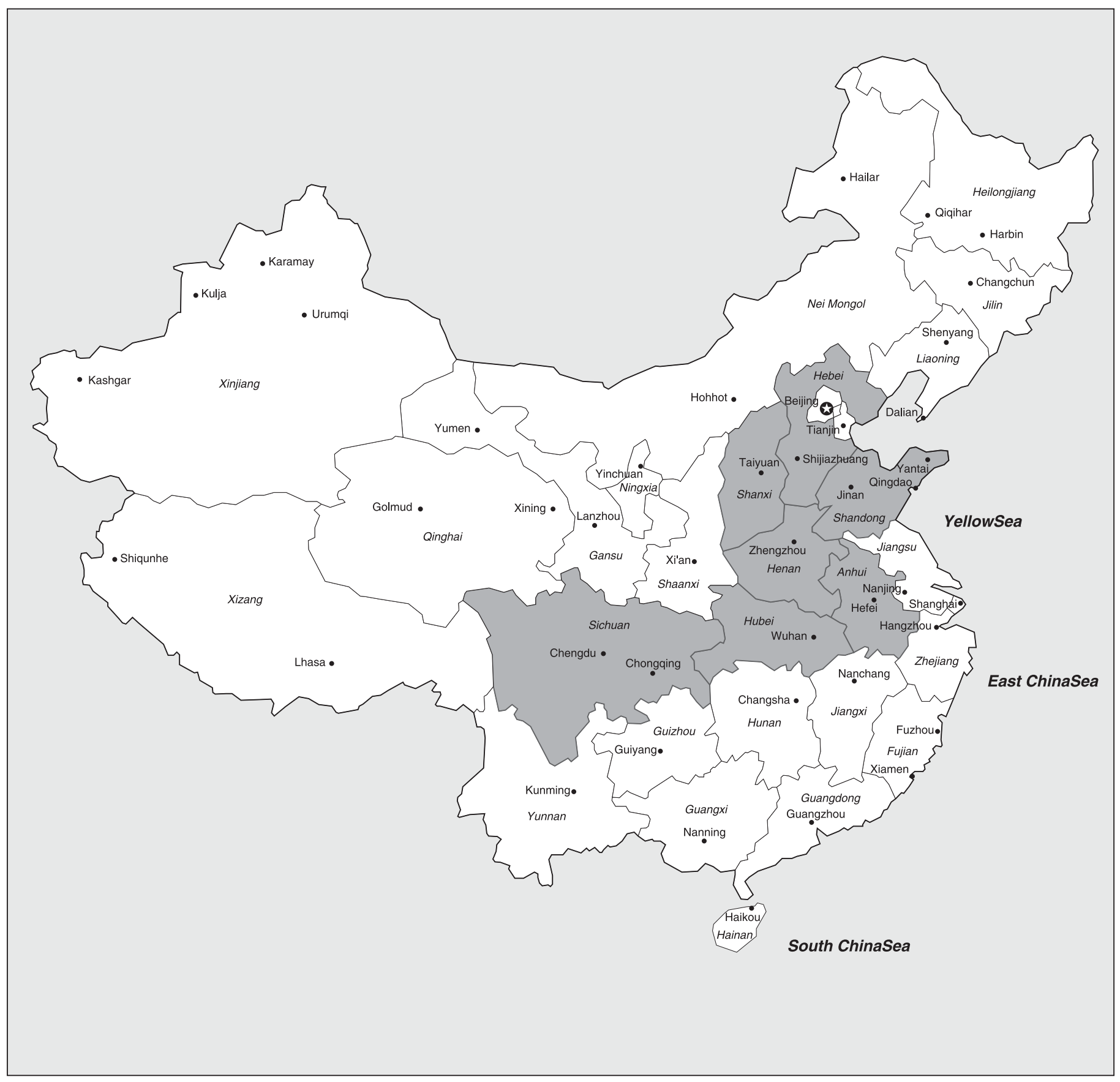

Fig. 1. Map of China. The provinces from which collections of Puccinia triticina were obtained are shaded. 
by using a LI-COR (Lincoln, NE) 4200 or 4300 DNA sequencer that was calibrated with IRDye 700 molecular weight size standards. DNA bands generated by each primer pair were standardized with other $P$. triticina isolates previously characterized using the same set of SSR primers. SSR genotypes were determined for each virulence phenotype from each province. If a virulence phenotype was found multiple times, two isolates were tested for SSR genotype. A total of 100 isolates were tested for SSR genotype. Isolates were further clone corrected by including only isolates with unique virulence phenotypes and SSR genotypes within each province. A total of 81 isolates were used in the final analyses.

Isolate genotypes were determined by using molecular weights of alleles at the 23 SSR loci. GENODIVE version 2.021b (Meirmans and van Tienderen 2004) was used to determine the number of SSR genotypes total and within each province. The $\mathrm{K}$ means clustering method in GENODIVE was used to assign SSR genotypes to groups of isolates. This method assigns individual genotypes to groups such that the within sum of squares distance of the individuals to the group centroid is minimized, and among groups sum of squares is maximized. A Bayesian approach was also used to group the SSR genotypes with STRUCTURE version 2.3 (Pritchard et al. 2000). Since STRUCTURE assumes that the populations are in HardyWeinberg equilibrium, the SSR genotypes were also examined for clustering using a two-dimensional principal coordinate (PCoA) plot in GENALEX 6 (Peakall and Smouse 2006). Previous studies with clonal populations of $P$. triticina using STRUCTURE placed SSR genotypes in groups that had high correlations with their virulence phenotypes (Ordoñez and Kolmer 2009). Values of $k$ (groups) from 1 to 15 were used, with 10 iterations for each level of $k$. The average $\ln \operatorname{Pr}(\mathrm{X} / \mathrm{K})$ was calculated for each $k$, and the differences between sequential values corresponding to $k 1$ to 15 were determined as described in Evanno et al. (2005). The number of SSR groups was determined by the $k$ interval with the largest change in $\ln \operatorname{Pr}(\mathrm{X} / \mathrm{K})$ and also by examination of SSR genotypes in the PCoA plot.

SSR genotypes in each province were characterized by number of alleles, number of effective alleles $\left(N_{e}\right)$, observed heterozygosity $\left(H_{O}\right)$, expected heterozygosity $\left(H_{E}\right)$, and fixation index $(F)$ that were calculated with GENALEX 6. Genetic differentiation of SSR genotypes between provinces was calculated via the analysis of molecular variance (AMOVA) in GENALEX 6 with 999 permutations of the data set using $R_{S T}$ (Valdes et al. 1995) that assumes a stepwise mutation model, and by $F_{S T}$ (Nei 1978) that assumes the infinite alleles model. Differentiation of virulence phenotypes between provinces was calculated with $\Phi_{P T}$, an analogous measure used for haploids. Isolates placed in SSR genotype groups were tested for differentiation of SSR genotypes and virulence phenotypes via AMOVA.

The SSR genotypes and virulence phenotypes were tested for correlation using a Mantel test in GENALEX 6. MULTILOCUS version 1.3 (Agapow and Burt 2001) was used to assess linkage disequilibria among the SSR genotypes using the index of association $\left(I_{A}\right)$, and also with a measure corrected for the number of loci, $r_{D}$. Tests of departure from random mating for both indices were done with 1,000 randomizations of the data set.

\section{RESULTS}

A total of 155 isolates from the seven provinces were tested for virulence phenotype. Forty-eight virulence phenotypes in total were described across all the provinces. Sichuan and Shandong provinces with 28 isolates tested, had the highest number of virulence phenotypes with 15 (Table 1), while Hubei province with only four isolates tested, had two virulence phenotypes. None of the 48 virulence phenotypes were found in all provinces. Phenotype FCBQQ with virulence to $L r 2 c, L r 3, L r 26, L r B, L r 10, L r 3 b g$, and $L r 14 b$ was found in all provinces except Shanxi and Hubei, and was the most common phenotype across China at $22.6 \%$ of all isolates tested (Supplementary Table 2). PCGLN with virulence to $L r l$, $L r 2 c, L r 3, L r 26, L r 11, L r B, L r 3 b g$, and $L r 20$ was found in all provinces except Henan and Hubei and was the second most common phenotype at $9.7 \%$ of isolates. PCGLL with virulence to $L r 1, L r 2 c, L r 3, L r 26, L r B$, and $L r 3 b g$ was found in Shanxi, Sichuan, and Shandong provinces and was the third most common phenotype at $7.7 \%$ of isolates. There was very little difference in virulence of isolates overall among the seven provinces based on Nei's genetic distance (Supplementary Fig. 1). The overall differentiation of virulence phenotypes across China for the 81 isolates analyzed after the final clone correction was nonsignificant with $\Phi_{P}=0.055(P=0.181)$. Only the Sichuan-Anhui province pair was significantly differentiated for virulence phenotype with $\Phi_{P T}=0.097(P=0.027)$.

All but 4 of the 155 tested isolates were virulent to $\operatorname{Lr} 26$ (Supplementary Table 3). None of the isolates had virulence to genes $L r 18$ or Lr24. Only single isolates were virulent to $\operatorname{Lr} 9$ and Lr16, only four isolates were virulent to $L r 28$, and seven isolates were virulent to $L r 3 k a$. Virulence to all other $L r$ genes varied across provinces at $>5 \%$ total frequency.

After clone correction for virulence phenotypes in each province, 100 isolates were tested for SSR genotype. Genotyping the isolates with 23 primer pairs yielded 36 SSR genotypes. Additional clone correction for isolates within each province based on virulence phenotype and SSR genotypes reduced the total number of isolates analyzed for SSR variation to 81 . Sichuan province had the highest number of SSR genotypes with 11, while Hubei province had the smallest number of genotypes with two (Table 1).

The SSR genotypes of the 81 isolates did not group into distinct provincial groups in a PCoA plot (not shown). Isolates from different provinces with identical or similar virulence phenotypes also had similar or identical SSR genotypes. Twelve SSR genotypes were found in more than one province (Table 2). Isolates with SSR genotype A were found in Shandong, Henan, and Hebei provinces. Isolates with SSR genotype A and MCGNS virulence phenotype were found in Shandong and Hebei provinces. Similarly, multiple isolates found within each of the SSR genotypes B, C, E, F, G, H, I, J, $\mathrm{K}, \mathrm{L}$, and $\mathrm{M}$ also had identical phenotypes that were found in more than one province. A few isolates with identical SSR genotypes but with different virulence phenotypes were found in different provinces. Isolates of phenotype TCBSS with SSR genotypes J, L, and $\mathrm{M}$ were found in Hebei, Hebei, and Shandong provinces, respectively. The AMOVA indicated no overall differentiation of SSR genotypes between provinces, with an overall $F_{S T}=0.008$ $(P=0.35)$ and $R_{S T}=0.00(P=0.45)$. Only the Shanxi-Henan pair of provinces had significant differentiation with $F_{S T}=0.046(P=$ $0.04)$ and $R_{S T}=0.13(P=0.03)$.

The averages of the single-locus parameters for the $P$. triticina genotypes from the seven provinces are given in Table 3 . There was very little difference among provinces (excluding Hubei province due to low sample size) for number of alleles, effective number of alleles, Shannon diversity (I) of SSR genotypes, observed heterozygosity $\left(H_{O}\right)$, expected heterozygosity $\left(H_{E}\right)$, and inbreeding coefficient $(F)$. Isolates in all provinces had significantly greater than expected levels of heterozygosity that resulted in significant

TABLE 1. Virulence phenotypes and simple sequence repeat (SSR) genotypes of Puccinia triticina isolates from seven provinces in China

\begin{tabular}{|c|c|c|c|c|c|c|c|c|}
\hline & Shanxi & Sichuan & Hebei & Henan & Shandong & Anhui & Hubei & Total \\
\hline Number of isolates & 27 & 28 & 28 & 23 & 28 & 17 & 4 & 155 \\
\hline Number of virulence phenotypes & 14 & 15 & 10 & 7 & 15 & 10 & 2 & 48 \\
\hline Number of SSR genotypes & 9 & 11 & 10 & 8 & 9 & 8 & 2 & 36 \\
\hline
\end{tabular}


negative values of the inbreeding coefficient. The 36 SSR genotypes were in a high state of disequilibrium with an $I_{A}$ of $1.99(P<0.001)$ and $r_{D}$ of $0.095(P<0.001)$.

TABLE 2. Twelve simple sequence repeat (SSR) genotypes of Puccinia triticina and related virulence phenotypes found in different provinces in China

\begin{tabular}{|c|c|c|}
\hline SSR genotype & Virulence phenotype & Province \\
\hline A & CCGNS & Shandong \\
\hline A & MCGNS & Shandong \\
\hline A & MCGLS & Shandong \\
\hline A & MCGSN & Henan \\
\hline A & MCGSS & Henan \\
\hline A & MCGNS & Hebei \\
\hline A & MCGNN & Hebei \\
\hline B & SCDDG & Anhui \\
\hline B & SCDNG & Hebei \\
\hline B & SCDNG & Shanxi \\
\hline $\mathrm{C}$ & KCBJT & Sichuan \\
\hline $\mathrm{C}$ & KCBJT & Shanxi \\
\hline E & FBBQQ & Shandong \\
\hline E & FBBQQ & Shanxi \\
\hline $\mathrm{F}$ & FCBQQ & Anhui \\
\hline $\mathrm{F}$ & FCDQQ & Anhui \\
\hline F & FCBQQ & Shandong \\
\hline $\mathrm{F}$ & FCBQQ & Henan \\
\hline F & FCBQQ & Hebei \\
\hline $\mathrm{F}$ & FCDQQ & Sichuan \\
\hline F & FHDQQ & Sichuan \\
\hline F & FCBQQ & Sichuan \\
\hline G & PCGLN & Anhui \\
\hline G & PCJLL & Anhui \\
\hline G & PCGLL & Shandong \\
\hline G & PCGLN & Shandong \\
\hline G & PCJQL & Shandong \\
\hline G & PCJLL & Shandong \\
\hline G & PCGLN & Hebei \\
\hline G & PCGLN & Sichuan \\
\hline G & PCGLL & Sichuan \\
\hline G & PCGLL & Shanxi \\
\hline G & PCJLN & Shanxi \\
\hline G & PCGLN & Shanxi \\
\hline G & PCJLL & Shanxi \\
\hline G & PCJLN & Shanxi \\
\hline G & MCJLL & Shanxi \\
\hline $\mathrm{G}$ & PCJLS & Shanxi \\
\hline $\mathrm{H}$ & LCGNJ & Hubei \\
\hline $\mathrm{H}$ & LCGNJ & Anhui \\
\hline $\mathrm{H}$ & NCGNJ & Anhui \\
\hline I & NCDSG & Henan \\
\hline I & SCDSG & Anhui \\
\hline $\mathrm{J}$ & TCDQS & Shandong \\
\hline $\mathrm{J}$ & TCDQS & Henan \\
\hline $\mathrm{J}$ & TCBSS & Hebei \\
\hline $\mathrm{J}$ & TCBQN & Hebei \\
\hline K & TCDGQ & Sichuan \\
\hline K & TCDNQ & Sichuan \\
\hline $\mathrm{L}$ & TCBSS & Hebei \\
\hline $\mathrm{L}$ & TCBGS & Shanxi \\
\hline M & TCBNS & Shandong \\
\hline M & TCBSS & Shandong \\
\hline M & TCDSS & Henan \\
\hline
\end{tabular}

Clustering of isolates in GENODIVE using $k$ means criteria did not result in any meaningful grouping, as the optimal number of groups was always 15 , which was the maximum value of $k$ tested. With the results from STRUCTURE, the isolates were placed into three groups of SSR genotypes based on the change in $\ln \operatorname{Pr}(\mathrm{X} / \mathrm{K})$ and the grouping of SSR genotypes in the PCoA plot (Fig. 2A). Thirty-six isolates were assigned to SSR group CN1, 32 isolates to $\mathrm{CN} 2$, and 13 isolates to $\mathrm{CN} 3$. The inferred ancestry of isolates within each group was high with only five isolates in CN1 with ancestry $<0.95$ and one isolate in $\mathrm{CN} 2$ with ancestry $<0.95$. Isolates in the three CN SSR groups were significantly differentiated with an overall $F_{S T}=0.22(P<0.001)$ and $R_{S T}=0.31(P<0.001)$ (Table 4$)$. Isolates in the three CN SSR groups were also significantly differentiated for virulence with an overall $\Phi_{P}=0.28(P<0.001)$. The PCoA plot of virulence phenotypes identified by CN SSR groups is shown in Figure 2B. Virulence to $L r 1, L r 2 a, L r 2 c, L r 3$, Lr26, Lr10, Lr14a, Lr14b, and Lr20 varied significantly $(P<0.05)$ between the CN SSR groups (Table 5). The virulence phenotypes and SSR genotypes had a Mantel correlation of $0.43(P<0.001)$.

\section{DISCUSSION}

The P. triticina collections examined in this study across seven major wheat producing provinces of China were highly related for virulence phenotypes and for SSR genotypes. The overall population was highly variable for both virulence and molecular polymorphism yet the variation was widely distributed across the regions. The seven provinces from which $P$. triticina collections were obtained account for $74 \%$ of the wheat production in China (USDA-FAS). Winter wheat is $95 \%$ of the total wheat crop in China, with spring wheat $(<5 \%$ of the crop) grown in the northern and western regions. The seven provinces are continuously adjacent with no significant geographical barriers between them. This major agricultural production area in China includes the Yangtze and Yellow River valleys. The geographic continuity of this region likely contributed to the lack of differentiation in the P. triticina populations as urediniospores could be widely dispersed across the provinces with no geographic barriers such as mountain ranges or deserts that would result in restricted movement of urediniospores across the region.

The host population may also have similar if not identical selective effects on the P. triticina populations in the different provinces. Almost all of the isolates tested were virulent to $L r 26$ that is present on the $1 \mathrm{~B} / 1 \mathrm{R}$ wheat-rye translocation. This gene was postulated to be present in 44 of 102 Chinese cultivars and breeding lines (Li et al. 2010), and in 81 of 163 Chinese wheat genotypes in another study (Singh et al. 1999). The $1 \mathrm{~B} / 1 \mathrm{R}$ translocation is common in wheat lines developed by CIMMYT and has been in Chinese winter wheat cultivars since the 1970s (Liu and Chen 2012). Singh et al. (1999) also postulated the presence of Lr16 in many Chinese wheat genotypes. Only one isolate in this study had complete virulence to Lrl6, yet many of the isolates had intermediate infection type of $22^{+}$of small to moderate uredinia surround by chlorosis. Cultivars with $L r 16$ have been grown in China in different provinces since 2000 (Liu and Chen 2012). Phenotypes of P. triticina with intermediate infection types to $\operatorname{Lrl6}$ would still have

TABLE 3. Average of single locus diversity parameters of simple sequence repeat (SSR) genotypes of Puccinia triticina from seven provinces in China

\begin{tabular}{|c|c|c|c|c|c|c|}
\hline Province & Number of alleles & Effective number of alleles & Shannon I & $H_{O}$ & $H_{E}$ & $F$ \\
\hline Shanxi & $3.43(0.35)^{\mathrm{a}}$ & $2.14(0.18)$ & $0.83(0.09)$ & $0.60(0.07)$ & $0.47(0.04)$ & $-0.24^{\mathrm{b}}(0.08)$ \\
\hline Sichuan & $3.30(0.37)$ & $2.42(0.27)$ & $0.88(0.10)$ & $0.62(0.06)$ & $0.49(0.05)$ & $-0.25^{\mathrm{b}}(0.05)$ \\
\hline Hebei & $3.30(0.36)$ & $2.18(0.23)$ & $0.83(0.09)$ & $0.58(0.60)$ & $0.47(0.40)$ & $-0.22^{\mathrm{b}}(0.07)$ \\
\hline Shandong & $2.96(0.28)$ & $2.18(0.19)$ & $0.81(0.09)$ & $0.59(0.07)$ & $0.47(0.04)$ & $-0.28^{\mathrm{b}}(0.08)$ \\
\hline Anhui & $3.26(0.36)$ & $2.34(0.27)$ & $0.84(0.10)$ & $0.61(0.07)$ & $0.47(0.05)$ & $-0.28^{\mathrm{b}}(0.06)$ \\
\hline Hubei & $2.0(0.00)$ & $2.22(0.17)$ & $1.97(0.17)$ & $0.66(0.08)$ & $0.58(0.07)$ & $-0.41^{\mathrm{b}}(0.07)$ \\
\hline
\end{tabular}

a Standard error.

b Significant at $P<0.05$. 
some reproductive advantage compared with isolates with much lower infection types of hypersensitive flecks and very small uredinia which is also characteristic of Lrl6 to certain isolates. Li et al. (2010) and Singh et al. (1999) also postulated the presence of $L r 1, L r 2 a, L r 3$, Lr3bg, Lr10, Lr14a, Lr17a, Lr18, Lr20, Lr23, and Lr24 in Chinese wheat cultivars. The $P$. triticina isolates in this study had virulence to all of these genes except for $\mathrm{Lr} 18$ and $\mathrm{Lr} 24$.

The $P$. triticina population in China had many characteristics of a clonally reproducing population (Halkett et al. 2005). There were high levels of observed heterozygosity $\left(H_{O}\right)$ relative to the heterozygosity expected $\left(H_{E}\right)$ under Hardy Weinberg equilibrium, high levels of linkage disequilibrium of SSR genotypes, and significant correlation between virulence and molecular genotypes. Other worldwide populations of $P$. triticina also have these characteristics of clonally reproducing populations. The most compatible alternate host for $P$. triticina, T. speciosissimum is native to the Mediterranean region and is not naturally present in other parts of the world. Despite the lack of a compatible alternate host to complete the sexual cycle, $P$. triticina populations in China and elsewhere are highly variable for both virulence and molecular markers. P. triticina can survive as mycelial infections during the winter on fall planted wheat and urediniospores can increase rapidly in the spring with the onset of warmer temperatures. Thus large populations are present across a wide geographic area that increases the probability those individuals with favorable mutations for virulence or at SSR loci will survive and increase.

Continental populations of $P$. triticina have been characterized by the presence of distinct groups of SSR genotypes that also differ significantly for virulence to leaf rust resistance genes. In Europe eight distinct SSR groups were defined (Kolmer et al. 2012) and in North America (Ordoñez and Kolmer 2009) six groups were characterized. The different SSR groups likely represent different introductions of $P$. triticina that have occurred in the various regions. In the United States and Canada, isolates with virulence to Lr17, Lr3bg, and Lr37 were found in large numbers starting in 1996 (Kolmer 1998; Long et al. 2000). These isolates also had distinct amplified fragment length polymorphism (Kolmer 2001) and SSR (Ordoñez and Kolmer 2009) genotypes compared with other isolates in North America, which indicated that these genotypes were likely introduced to the U.S. and Canada. Isolates with the same virulence and identical SSR genotypes (J. Kolmer, unpublished data) also spread to South America (Ordoñez et al. 2010), France, and Turkey (Kolmer et al. 2012) since the mid-1990s. However these isolates were not found in China where only three SSR groups were found. The lower number of SSR groups present in China suggests that fewer P. triticina genotypes have been introduced to this region and that this population is somewhat isolated from other $P$. triticina populations. A further comparison of SSR genotypes and virulence phenotypes between the major continental regions where wheat is grown will provide more insight on the relationship between the Chinese $P$. triticina population and those in other regions.

Virulence surveys of $P$. triticina have been conducted in China in recent years. From 2000 to 2006, PHT (virulent to $\operatorname{Lrl}, \operatorname{Lr} 2 c, \operatorname{Lr} 3$, Lr16, Lr26, Lr3ka, Lr11, Lr17, and Lr30), THT (virulent to Lrl,

TABLE 4. $F_{S T}, R_{S T}$, and $\Phi_{P T}$ values of genetic differentiation of simple sequence repeat (SSR) genotypes and virulence phenotypes of Puccinia triticina groups in China defined by SSR genotypes in STRUCTURE

\begin{tabular}{lccc}
\hline STRUCTURE group pair & $F_{S T}$ & $R_{S T}$ & $\Phi_{P T}$ \\
\hline CN1-CN2 & $0.17^{\mathrm{a}}$ & $0.28^{\mathrm{a}}$ & $0.17^{\mathrm{a}}$ \\
CN1-CN3 & $0.22^{\mathrm{a}}$ & $0.30^{\mathrm{a}}$ & $0.38^{\mathrm{a}}$ \\
CN2-CN3 & $0.35^{\mathrm{a}}$ & $0.59^{\mathrm{a}}$ & $0.44^{\mathrm{a}}$ \\
Overall & $0.22^{\mathrm{a}}$ & $0.31^{\mathrm{a}}$ & $0.28^{\mathrm{a}}$ \\
\hline
\end{tabular}

a Significant at $P<0.05$.
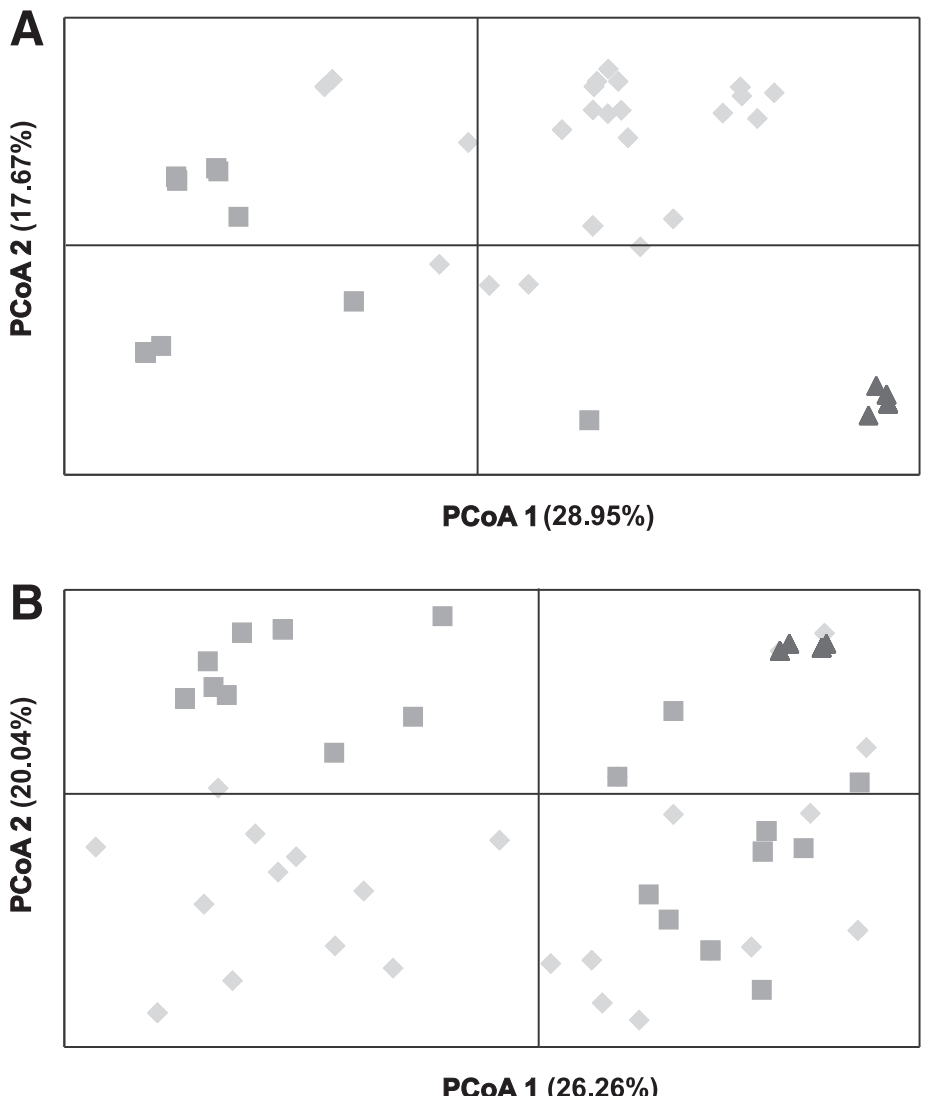

CN1

CN2

$\triangle \mathrm{CN} 3$

PCOA $1(26.26 \%)$

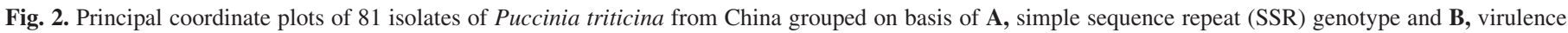
phenotype. $\mathrm{CN} 1, \mathrm{CN} 2$, and $\mathrm{CN} 3$ refer to SSR genotype groups. 
Lr2a, Lr2c, Lr3, Lr16, Lr26, Lr3ka, Lr11, Lr17, and Lr30), and PHJ (virulent to $L r 1, L r 2 c, L r 3, L r 16, L r 26, L r 11$, and $L r 17$ ) were the three most common virulence phenotypes and were found across all regions with no geographic differentiation (Liu and Chen 2012). In the current study FCB (virulent to $L r 2 c, L r 3$, and $L r 26$ ) and PCG (virulent to $L r 1, L r 2 c, L r 3, L r 26$, and $L r 11$ ) were the equivalent (based on virulence to 12 differentials) most common phenotypes across China. Differences between the two studies could be due to changes in the prevalent virulence phenotypes from 2006 to 2009, when most of the collections of this study were obtained. There could also be differences in interpreting low infection types conditioned by the Thatcher isogenic lines. Lines with genes $L r 11, L r 3 k a, L r l 6$, $L r 17$, and $L r 30$ often have intermediate infection types of moderate to large uredinia surrounded by chlorosis that could be interpreted or appear to be high infection types under certain greenhouse conditions. Data from 2000 to 2006 (Liu and Chen 2012) indicated that virulence to $L r 3 k a, L r l 6$, and $L r l 8$ were at frequencies $>50 \%$ across China. However, in the current study virulence to these genes were either not found or were at very low frequencies. In both the 2000 to 2006 data and the current study, virulence to $\operatorname{Lr} 9$ and $L r 24$ were not found or were at very low frequencies, and virulence to $\operatorname{Lr} 26$ was $>95 \%$.

In conclusion, the wide distribution of $P$. triticina genotypes across the major wheat production areas in China indicated a single geographic or epidemiological population. Urediniospores clonally produced in one province could easily be windborne to other provinces. In North America a similar situation is found in the Great Plains region, which is a single epidemiological region for $P$. triticina. Phenotypes that have virulence to resistance genes in hard red winter wheat cultivars that are grown in the southern states of Texas and Oklahoma are carried by the southerly winds in the spring and summer to the spring wheat area of Minnesota, South Dakota, and North Dakota (Kolmer and Hughes 2013). The use of wheat cultivars in one region can have a direct effect on the $P$. triticina population in a region thousands of kilometers distant. The use of wheat cultivars with different resistance genes that are grown in different areas of a single $P$. triticina epidemiological region can prolong the effective life span of these genes before virulent phenotypes increase to a point where the resistance is no longer effective. Wheat improvement programs in different regions of

TABLE 5. Frequency (\%) of Puccinia triticina isolates with virulence to lines of wheat with single genes for resistance in three groups of simple sequence repeat (SSR) genotypes in China

\begin{tabular}{|c|c|c|c|c|}
\hline Gene & CN1 & $\mathrm{CN} 2$ & CN3 & $\begin{array}{l}\text { Probability } \\
\text { difference }\end{array}$ \\
\hline Lrl & 81.0 & 100.0 & 0.0 & $0.00^{\mathrm{a}}$ \\
\hline$L r 2 a$ & 47.0 & 41.0 & 0.0 & $0.01^{\mathrm{a}}$ \\
\hline$L r 2 c$ & 67.0 & 97.0 & 100.0 & $0.00^{\mathrm{a}}$ \\
\hline Lr3 & 75.0 & 94.0 & 100.0 & $0.02^{\mathrm{a}}$ \\
\hline $\operatorname{Lr} 9$ & 0.0 & 0.0 & 0.0 & 1.00 \\
\hline Lr16 & 0.0 & 0.0 & 8.0 & 0.07 \\
\hline $\operatorname{Lr} 24$ & 0.0 & 0.0 & 0.0 & 1.00 \\
\hline $\operatorname{Lr} 26$ & 100.0 & 100.0 & 85.0 & $0.00^{\mathrm{a}}$ \\
\hline Lr3ka & 11.0 & 0.0 & 0.0 & 0.07 \\
\hline Lrl1 & 36.0 & 59.0 & 0.0 & $0.00^{\mathrm{a}}$ \\
\hline Lr17 & 25.0 & 50.0 & 39.0 & 0.10 \\
\hline Lr30 & 11.0 & 0.0 & 0.0 & 0.07 \\
\hline $\operatorname{LrB}$ & 88.9 & 84.4 & 100.0 & 0.32 \\
\hline Lr10 & 50.0 & 40.6 & 100.0 & $0.00^{\mathrm{a}}$ \\
\hline $\operatorname{Lr} 14 a$ & 80.6 & 15.6 & 0.0 & $0.00^{\mathrm{a}}$ \\
\hline $\operatorname{Lr} 18$ & 0.0 & 0.0 & 0.0 & 1.00 \\
\hline Lr3bg & 72.2 & 90.6 & 1.0 & $0.03^{\mathrm{a}}$ \\
\hline$L r 14 b$ & 88.9 & 37.5 & 100.0 & $0.00^{\mathrm{a}}$ \\
\hline Lr2O & 66.7 & 50.0 & 0.0 & $0.00^{\mathrm{a}}$ \\
\hline $\operatorname{Lr} 28$ & 8.3 & 0.0 & 0.0 & 0.14 \\
\hline $\begin{array}{l}\text { Total number of } \\
\text { isolates }\end{array}$ & 36 & 32 & 13 & \\
\hline
\end{tabular}

a Significant difference at $P<0.05$.
China may need to develop cultivars that differ in effective leaf rust resistance genes in order to slow the increase of virulent $P$. triticina phenotypes.

\section{ACKNOWLEDGMENTS}

I thank T. Zhang for collections of Puccinia triticina, and K. Xiao and M. Hughes for excellent technical assistance.

\section{LITERATURE CITED}

Agapow, P. M., and Burt, A. 2001. Indices of multilocus linkage disequilibrium. Mol. Ecol. Notes 1:101-102.

Baoqi, S., Zhang, A., and Bonjean, A. 2001. Chinese wheat pool. Pages 667699 in: The World Wheat Book. A. Bonjean and W. Angus, eds. Lavoisier, New York.

Chester, K. S. 1946. The Nature and Prevention of the Cereal Rusts as Exemplified in the Leaf Rust of Wheat. Chronica Botanica, Waltham, Massachusetts.

Duan, X., Enjalbert, J., Vautrin, D., Solignac, M., and Giraud, T. 2003. Isolation of 12 microsatellite loci, using an enrichment protocol, in the phytopathogenic fungus Puccinia triticina. Mol. Ecol. Notes 3:65-67.

Evanno, G., Regnaut, S., and Goudet, J. 2005. Detecting the number of clusters of individuals using multilocus genotype data: Linked loci and correlated allele frequencies. Mol. Ecol. 14:2611-2620.

German, S. E., and Kolmer, J. A. 1994. Virulence Phenotypes of Puccinia recondita f. sp. tritici in Uruguay. Plant Dis. 78:1139-1141.

German, S. E., Barcellos, A., Chaves, M., Kohli, M., Campos, P., and de Viedma, L. 2007. The situation of common wheat rusts in the Southern Cone of America and perspectives for control. Aust. J. Agric. Res. 58:620-630.

Goyeau, H., Halkett, F., Zapater, M. F., Carlier, J., and Lannou, C. 2007. Clonality and host selection in the wheat pathogenic fungus Puccinia triticina. Fungal Genet. Biol. 44:474-483.

Halkett, F., Simon, J. C., and Balloux, F. 2005. Tackling the population genetics of clonal and partially clonal organisms. Trends Ecol. Evol. 20: 194-201.

Johnson, T. 1956. Physiologic races of leaf rust of wheat in Canada 1931 to 1955. Can. J. Agric. Sci. 36:323-332.

Johnston, C. O., Caldwell, R. M., Compton, L. E., and Browder, L. E. 1968. Physiologic races of Puccinia recondita $\mathrm{f}$. sp. tritici in the United States from 1926 through 1960. USDA Tech. Bull. 1393:1-18.

Kolmer, J. A. 1998. Physiologic specialization of Puccinia recondita f. sp. tritici in Canada in 1996. Can. J. Plant Pathol. 20:176-181.

Kolmer, J. A. 2001. Molecular polymorphism and virulence phenotypes of the wheat leaf rust fungus Puccinia triticina in Canada. Can. J. Bot. 79: 917-926.

Kolmer, J. A., and Hughes, M. E. 2013. Physiological specialization of Puccinia triticina on wheat in the United States in 2011. Plant Dis. 97:1103-1108.

Kolmer, J. A., and Ordoñez, M. E. 2007. Genetic differentiation of Puccinia triticina populations in Central Asia and the Caucasus. Phytopathology 97: 1141-1149.

Kolmer, J. A., Ordoñez, M. E., Manisterski, J., and Anikster, Y. 2011. Genetic differentiation of Puccinia triticina populations in the Middle East and genetic similarity with populations in Central Asia. Phytopathology 101: 870-877.

Kolmer, J. A., Hanzalova, A., Goyeau, H., Bayles, R., and Morgounov, A. 2012. Genetic differentiation of the wheat leaf rust fungus Puccinia triticina in Europe. Plant Pathol. 62:21-31.

Kolmer, J. A., Mert, Z., Akan, K., Demir, L., Unsal, R., Sermet, C., Keser, M., Akin, B., and Morgounov, A. 2013. Virulence of Puccinia triticina in Turkey and leaf rust resistance in Turkish wheat cultivars. Eur. J. Plant Pathol. 135:703-716.

Li, Z. F., Xia, X. C., He, Z. H., Li, X., Zhang, L. J., Wang, H. Y., Meng, Q. F., Yang, W. X., Li, G. Q., and Liu, D. Q. 2010. Seedling and slow rusting resistance to leaf rust in Chinese wheat cultivars. Plant Dis. 94:45-53.

Liu, T. G., and Chen, W. Q. 2012. Race and virulence dynamics of Puccinia triticina in China during 2000-2006. Plant Dis. 96:1601-1607.

Long, D. L., and Kolmer, J. A. 1989. A North American system of nomenclature for Puccinia recondita f. sp. tritici. Phytopathology 79:525-529.

Long, D. L., Leonard, K. J., and Hughes, M. E. 2000. Virulence of Puccinia triticina on wheat in the United States from 1996 to 1998. Plant Dis. 84: 1334-1341.

Meirmans, P. G., and van Tienderen, P. H. 2004. GENOTYPE and GENODIVE: Two programs for the analysis of genetic diversity of asexual organisms. Mol. Ecol. Notes 4:792-794.

Morgounov, A., Rosseeva, L., and Koyshibayev, M. 2007. Leaf rust of spring wheat in Northern Kazakhstan and Siberia: Incidence, virulence, and breeding for resistance. Aust. J. Agric. Res. 58:847-853.

Nei, M. 1972. Genetic distance between populations. Am. Nat. 106:283-292. 
Nei, M. 1978. Estimation of average heterozygosities and genetic distance from a small number of individuals. Genetics 89:583-590.

Ordoñez, M. E., and Kolmer, J. A. 2009. Differentiation of molecular genotypes and virulence phenotypes of Puccinia triticina from common wheat in North America. Phytopathology 99:750-758.

Ordoñez, M. E., German, S. E., and Kolmer, J. A. 2010. Genetic differentiation within the Puccinia triticina population in South America and comparison with the North American population suggests common ancestry and intercontinental migration. Phytopathology 100:376-383.

Peakall, R., and Smouse, P. E. 2006. GENALEX 6: Genetic analysis in Excel. Population genetic software for teaching and research. Mol. Ecol. Notes 6: 288-295.

Pritchard, J. K., Stephans, M., and Donnelly, P. 2000. Inference of population structure using multilocus genotype data. Genetics 155:945-959.

Roelfs, A. P. 1989. Epidemiology of the cereal rusts in North America. Can. J. Plant Pathol. 11:86-90.
Roelfs, A. P., Singh, R. P., and Saari, E. E. 1992. Rust Diseases of Wheat: Concepts and methods of disease management. CIMMYT, Mexico, D.F.

Samborski, D. J. 1985. Wheat leaf rust. Pages 35-59 in: The Cereal Rusts Vol. 2. A. P. Roelfs and W. R. Bushnell, eds. Academic Press, Orlando, FL.

Singh, R. P., Chen, W. Q., and Ze, Z. H. 1999. Leaf rust resistance of spring, facultative, and winter wheat cultivars from China. Plant Dis. 83:644651.

Szabo, L. S., and Kolmer, J. A. 2007. Development of simple sequence repeat markers for the plant pathogenic rust fungus Puccinia triticina. Mol. Ecol. Notes 7:708-710.

Valdes, A. M., Slatkin, M., and Freimer, N. B. 1995. Allele frequencies at microsatellite loci: The stepwise mutation model revisited. Genetics 133: 737-749.

Wang, H. R. 1947. Notes on physiological specialization of leaf rust of wheat in China. Phytopathology 37:680-681. 